\title{
ANALISIS ANTOLOGI PUISI PESAN TUA KARYA HENDRA DJAFAR MENGGUNAKAN TEORI SEMIOTIC
}

\author{
Abdul Muttalib" ${ }^{*}$, Wahyuddin', Rina Riniawati2 \\ IUniversitas Al Asyariah Mandar \\ 2Universitas Bina Sarana Informatika \\ *Email: alifbatza@gmail.com
}

\begin{abstract}
This study aims to analyze the poetry anthology "Old Message" by Hendra Djafar using structuralism-semiotic theory. This type of qualitative descriptive research by conducting library research (library research) through relevant reading materials. The analysis was carried out on three poems, "I am a Orderly Poetry," Salawatku," and "Old Message" which are considered to represent the tendencies of Hendra Djafar's poetry in the types of ballads, odes and contemporary. The analysis of the three poems is then analyzed using the theory analysis are: 1). The dimensions of the icon are analyzed from the power of saying " $I$ " lyrics as a poet as well as acting as a dominantlooking narrator, 2). The index dimension implies that there is tension between the form and content of the poem, contradictions in the psychological dimension between messages and impressions, as well as between exclamations and criticisms, 3). Although the dimensions of arbitrary symbols are not widely found.
\end{abstract}

Keywords: poetry, anthological analysis, semiotic theory

\section{PENDAHULUAN}

Perbedaan mendasar studi kesusastraan dan studi keilmuan terletak pada citarasa bahasa yang digunakan. Pradopo (2007) mengungkapkan, bahasa keilmuan lebih mengutamakan kecemerlangan pada kandungan ilmiahnya, sedangkan bahasa pada karya kesusastraan memiliki kecenderungan bahasa bermuatan estetis, akustis dan metaforis. Kendati fungsi bahasa estetis kesusastraan akan lebih dominan, terutama ketika mengamati karya sastra bergenre puisi.

Seperti karya sastra puisi yang terhimpun dalam buku kumpulan (antologi) Pesan Tua karya Hendra Djafar yang lahir pada tanggal 12 April 1982 di Desa Pambusuang, Kecamatan Balanipa, Kabupaten Polewali Mandar, Provinsi Sualwesi Barat. Selain dikenal sebaga aktor dari komunitas Teater Palatto, Hendra Djafar tercatat, sudah dua kali meluncurkan buku kumpulan puisi. Buku 
pertamannya berjudul Prahara Bunga dan Pancaroba (2014) dan kumpulan puisi yang kedua berjudul Pesan Tua (2020).

Buku antologi puisi Pesan Tua karya Hendra Djafar berisi 54 puisi yang dominan bergaya ode, balada, dan kontenporer. Khusus penelitian ini akan mengkaji tiga puisi yang masing-masing mewakili gaya, ode balada dan kontenporer. Ketiga puisi yang dimaksudkan yakni puisi berjudul Pesan Tua, Aku Penyair Pesanan dan Salawatku yang akan dikaji menggunakan teori semiotic yang fokus pada kandungan makna puisi.

Sehingga untuk memahami puisi haruslah diperhatikan jalinan atau pertautan antar unsur-unsurnya sebagai bagian keseluruhan dari puisi. Terlebih menurut Nurweni (2016) ketika hendak melihat unsur puisi pada aspek makna menggunakan analisis semiotic. Sedangkan Hidayat (2014) mengungkapkan analisis semiotic lebih fokus melihat bahasa sebagai sistem tanda, dan setiap tanda itu tersusun dalam dua bagian, yakni: signifier (penanda) dan signified (petanda).

Unsur penanda merupakan unsur yang berfungsi untuk menandai sesuatu. Sedangkan petanda adalah objek yang ditandai oleh penanda. Secara umum kedua perangkat teori tersebut, menjadi dasar bagi penulis untuk menganilisis antologi puisi Pesan Tua karya Hendra Djafar. Adapun penelitian yang relevan dengan materi penelitian dan sudah dijalankan yakni: karya Hasanah (2013) berjudul "Karakteristik Strukturalisme-SemioticPuisi Karya D. Zawawi Imron," sementara penelitian Indra (2018) berjudul "Sastra Lisan Krinok: Kajian Strukutral dan Semiotik."

\section{METODE PENELITIAN}

Jenis penelitian analisis deskriptif kualitatif dengan metode library recearch yaitu dengan cara studi lewat bahan bacaan yang relevan yang mendukung penelitian, Pradopo (2007). Sedangkan instrumen penelitian secara kualitatif penelitian ini mencoba mendeskripsikan karakteristik puisi Hendra Djafar dalam antologi puisi "Pesan Tua" menggunakan teori semiotic yang fokus menafsir aspek signifier (penanda) dan signified (petanda) pada teks puisi yang akan dikaji, Pradopo (2007). Data yang dimaksud dalam rancangan penelitian ini yakni: puisi dalam buku antologi pesan tua karya Hendra Djafar.

\section{HASIL DAN PEMBAHASAN}

\section{Analisis Semiotik Puisi "Aku Penyair Pesanan"}

Analisis semiotik adalah sebuah kajian yang menganalisis sistem tanda dalam puisi, Pradopo (2007). Dalam pengertian tanda dikenal dua prinsip yakni: penanda (signifier) dan petanda (signified). Hubungan antara penada dan petanda dikenal tiga jenis tanda. Tanda sebagai ikon, tanda sebagai indeks dan tanda sebagai simbol. Ketiga aspek ini yang akan digunakan penulis untuk menganalisis 
data dari ketiga puisi Hendra Djafar yang termaktub dalam antologi puisi "Pesan Tua".

AKU PENYAIR PESANAN

aku rangkai kata bukan untuk mau dikata /

apalagi untuk mengataimu //

aku rangkai kata bukan jadi siapa /

apalagi menjadi siapa pun.

Aspek simbol pada larik pertama di bait pertama, aku lirik pada teks "aku" bukanlah "rangkai kata" karena kata "aku" adalah manusia yakni "aku" lirik itu sendiri sementara "rangkai kata" bukan lah manusia. Tapi tetap memiliki hubungan alamiah mengingat, salah satu aspek penciri dari manusia yang lazim berkata (indeks). Lalu ikonya di mana? Secara cerdik dan piawai penyair menggunakan metafora "aku" sebagai petanda ((signified)) dan penandanya ((signifier) untuk menandai hubungan antara dirinya, yang secara otonom sebagai penyair yang memproduksi puisi menggunakan kata-kata.

Penyair dengan "aku" lirik sudah sangat tepat mengadaikan dirinya dengan "kata", tanpa perlu menggunakan majas smile; seperti, bak dan laksana. Aku lirik dalam puisi Hendra Djafar jika meminjam istilah Sugiharto (2007) seperti "memberi efek maksimal dengan usaha yang minimal." Meski pada larik kedelapan (8) bait kedua (2); dipesan air mata cair dalam doa. Diksi "air" dan "cair" terasa memiliki logika cacat karena sifat cair secara jelas dan terang benderang dimiliki oleh air, seperti "air mata".

Artinya pada larik ini penyair luput menimbang secara eksplisit teks "air" dan "cair." Pada diksi pembuka larik sembilan dan sebelas, penulis juga terbilang "aneh" memaknai diksi "apalah" yang berulang sampai dua kali. Menurut Pradopo (2007), bahasa adalah media komunikasi lapis pertama, sedangkan sastra adalah lapis kedua. Keduanya memiliki konvensi, kaidah, sifat dan ciri tertentu, terlebih jika menulis puisi sebagai aktivitas pencurahan jiwa yang padat secara liris dan bersifat sugestif. Diksi "apalah" terbilang lemah pada aspek sugestif terlebih dalam dimensi akustik. 


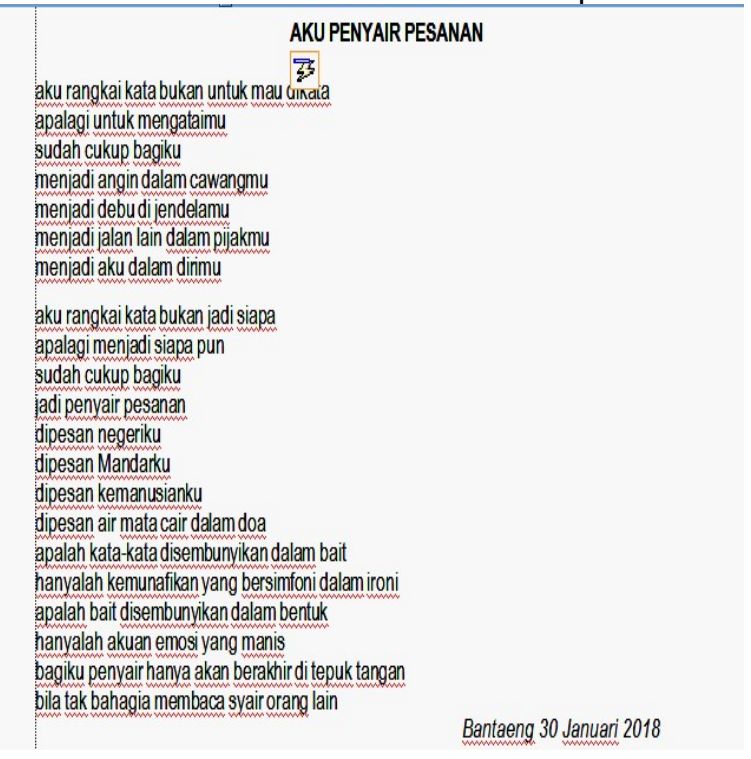

Gambar 1. Puisi "Aku Penyair Pesanan"

\section{Analisis Semiotik Puisi "Salawatku"}

\section{$S A L A W A T K U$}

Ya Rasul...

aku bersalawat padamu /

dengan menegaskan timbangan daganganku//

dengan tidak mencerca saudara muslimku //

dengan tidak mencuri di laci negara //

dengan tidak menyebarkan berita mawar yang berbau merica

Puisi kedua Hendra Djafar berjudul "Salawatku" jika dianalisis menggunakan indeks semiotik, pada larik ketiga, kelima, dan kesepuluh kaifiat salawat diyakini "aku" lirik akan menjadi wasilah (penghubung) dalam menyampaikan permohonan kepada Allah SWT. Salawat yang tidak peril ditimbang amal dan ibadahnya lewat pendekatan materialis "timbangan daganganku", justru sedianya salawat yang dilantunkan menjaga lisan agar tidak "mencerca saudara semuslim" mencegah tindakan korupsi "mencuri di laci negara" bahkan tidak berbuat dan menyebar gibah serta hoax, "berita mawar berbau merica." 
Secara denotatif "timbangan daganganku" coba membandingkan antara ibadah dan surga, antara dosa dan neraka, padahal keduanya tidak memiliki kolerasi logis jika diamati sebagai simbol dalam kajian semiotik. Karena prilaku ibadah dengan terminologi surga dan neraka tidak jauh lebih baik dari sifat "timbanganku." Justru lewat salawat, aku lirik berharap syafaat dan cinta kasih Rasulullah Muhammad SAW agar memperelah rahmat Allah SWT, karena puisi "Salawat" secara utuh sudah menjadi ikon para pecinta dalam mencapai nilai penghambaanya "bersama kerinduan Bilal bin Rabbah."

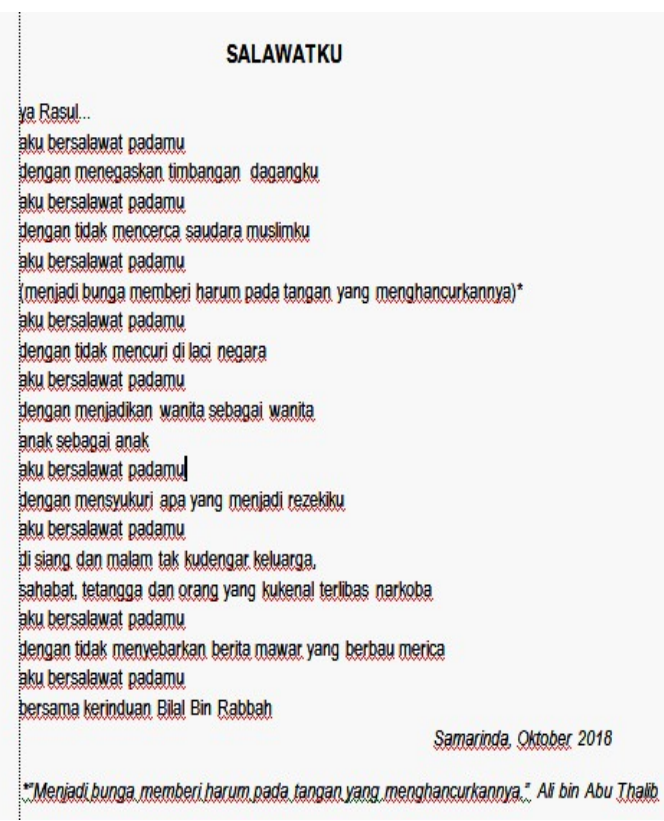

Gambar 2. Puisi "Salawatku"

\section{Analisis Semiotik Puisi "Pesan Tua"}

Puisi ketiga Hendra Djafar "Pesan Tua" dari sisi bentuk dan isi mensyaratkan doa dan harapan besar penyair kepada Alwan Falih Mawarraq serupa arti dari namanya; menjulang tinggi imannya dan disegani. Pengembaraan puitik penyair dibuktikan lewat buku kumpulan puisi pertamanya berjudul, Prahara Bunga dan Pancaroba (2014) dan buku kedua Pesan Tua (2020)dan titimangsa kapan dan dimana puisi dibuat. Dari ketiga puisi yang dianalisis penulis, menemukan titimangsa daerah Bantaeng, Provinsi Sulawesi Selatan, kota Samarinda, Provinsi Kalimantan Timur, dan di Mandar, Provinsi Sulawesi Barat sebagai tempat penciptaan puisinya. 


\title{
Pesan Tua
}

\author{
Alwan Falih Mawarraq / \\ dalam peperanganmu kelak // \\ hadapkan tubuhmu pada Ka'bah'// \\ hadapkan hatimu pada Bait al Makmur // \\ hadapkan nyawamu pada aras kursia // \\ hadapkan rahasimu pada Allah semata.
}

Pengembaraan fisik, ke tempat-tempat yang ada pada titikmangsa dari ketiga puisi yang diulas dalam penelitian ini, sekiranya menjadi titik tolak bagi peneliti untuk mengamati bentuk penjelajahan "aku" lirik berdimensi rohani sehingga "dalam; berperan melawan hawa nafsu. "Dalam peperanganmu kelak" Alwan Falih Mawarraq yang tidak mesti bermakna "peperangan" fisik semata, tapi berpeluang bermakna peperangan rohani melawan hawa nafsu.

Segeralah kembali kepada satu titik kesatuan. Di mana tempat itu? "Ka'ba" sebagai arah sekaligus Kiblat sewaktu mendirikan salat, sebab antara arah "kiblat" dan "tubuh" menghadap bermakna indeks dalam kajian semiotik puisi. Jika kiblat manusia adalah "Ka'ba," maka pemahaman dan keyakinan ummat Islam Baitul Makmur sebagai perlambangan dari Kiblat penghuni langit, sebagai ikon dalam puisi ini.

\begin{tabular}{|c|c|c|}
\hline \multicolumn{3}{|c|}{ PESAN TUA } \\
\hline 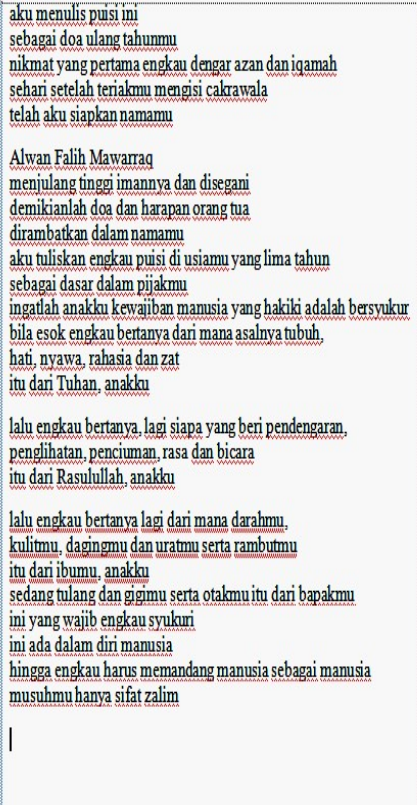 & 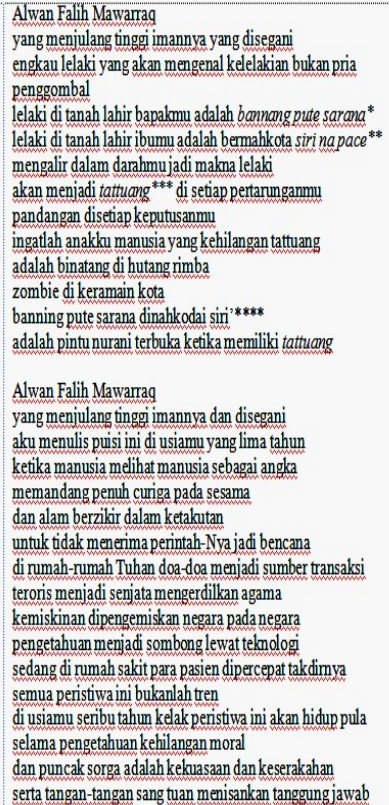 & 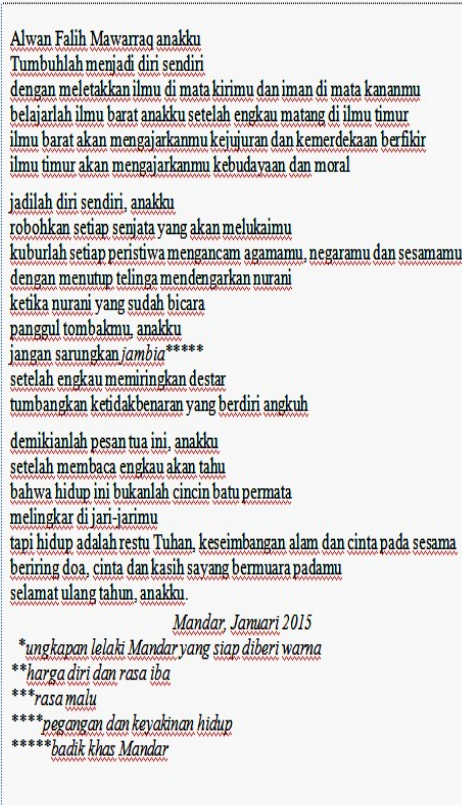 \\
\hline
\end{tabular}

Gambar 3. Puisi "Pesan Tua" 


\section{SIMPULAN}

Berdasarkan uraian hasil dan pembahasan, maka analisis ketiga puisi

"Aku Penyair Pesanan," "Salawatku" dan "Pesan Tua" menggunakan teori semiotic yakni: 1). Dimensi ikon dianalisis dari daya ucap "aku" lirik sebagai penyair sekaligus bertindak selaku narator terlihat dominan, 2). Dimensi indeks secara tersirat menampilkan ketegangan antara bentuk dan isi puisi, pertentangan dalam dimensi psikologis antara pesan dan kesan, serta antara seruan-kritikan, 3). Meski pada dimensi simbol bermakna arbitrer tidak banyak ditemukan.

\section{SARAN DAN REKOMENDASI}

Berdasarkan simpulan di atas maka penelitian seperti ini ke depannya, diharapkan lebih banyak lagi menganalisis puisi menggunakan teori semiotic. Aktivitas penganalisisan puisi dapat dimaknai sebagai usaha menumbuhkan ruang apresiasi puisi secara lebih luar. Ruang apresiasi puisi dibutuhkan tidak hanya bagi para penyair untuk menakar kwalitas puisinya, tapi juga dibutuhkan para peneliti agar dapat dianalisis yang kelak hasilnya dapat menjembatani pemahaman bagi para penikmat puisi.

\section{DAFTAR PUSTAKA}

Djafar, Hendra, 2020. Kumpulan Puisi Pesan Tua. Mammesa (Media Masyarakat Transparansi Indonesia). Polewali Mandar Sulawesi Barat.

Hasanah, Muakibatul, 2013. Karakteristik Strukturalis-Semiotik Puisipuisi Karya D. Zawawi Imron. Litera: Jurnal Penelitian Bahasa, Sastra dan Pengajaran. Vol $12 . \quad$ No 2. https://journal.uny.ac.id/index.php/litera/article/view/1589.

Hidayat, Rahmat, 2014. Analisis Semiotika Makna Motivasi Pada Lirik Lagu "Laskar Pelangi" Karya Nidji. Editor: Jurnal Komunikasi. Vol. 5 No. 2. https://ejournal.ilkom.fisip-unmul.ac.id/site/wpcontent/uploads/2014/02/ejournal\%20yayat \%20(02-22-14-05-15-40).pdf

Indra, Feerlie Moonthana, 2018. Sastra Lisan Krinok: Kajian Strukutral dan Semiotik. Dikbastra: Jurnal Pendidikan Bahasa dan Sastra. Vol. 1 No 1. https://www.online-journal.unja.ac.id/dikbastra/article/view/5834.

Nurweni Saptawuryandari, 2016. Analisis Semiotik Puisi Chairil Anwar. Jurnal

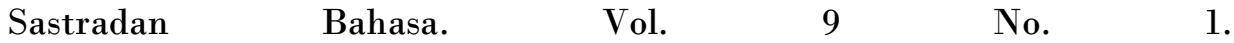
https://core.ac.uk/download/pdf/229284948.pdf.

Pradopo, Rachmat Djoko, 2007. Beberapa Teori Sastra, Metode Kritik, dan Penerapannya. Pustaka Pelajar. Yogjakarta.

Sugiharto, Bambang. 2007. Ripin: Cerpen Pilihan Kompas. PT. Kompas Media Nusantara. 